\title{
University Students' Perception in Using English Swear Words
}

\author{
Nida Husna \\ Syarif Hidayatullah State Islamic University \\ Jakarta, Indonesia \\ nida.husna@uinjkt.ac.id
}

\begin{abstract}
The present study was focused to find out the students' perspective in using the words that were included as socially impolite. The subject was the students of the fifth semester at the English Education Department, State Islamic University, Jakarta. The data were collected using a questionnaire that was given two times. The findings were gathered to get the information about the students' habits in using the profanity words, including which words that they used most to state their uneasy feeling or anger, how they acquired the words, and how did they feel after using them. The result showed that there were 10 swear words that were acknowledged by the students and several of them were considered very offensive, however, they admitted that it was difficult not to use them. It was also found out that the movie has the most influence in acquiring those words.
\end{abstract}

Keywords: swear words, students, culture, psychology

\section{INTRODUCTION}

English as one of the leading languages in the world is learned both as foreign and second language. The use of English around the globe has become very common as lingua franca. Many people learn to be able to speak the language for various reasons. The English Language Teaching (ELT) becomes more than just finding the best method to help people able to learn the language more easily, it also becomes the agent of spreading the culture of the language itself or the country where this language is spoken most. Since "A language can be described in two aspects - as a means of communication and as an expression of spiritual culture of a nation" (Bartkevičienè \& Petniūnienè, 2008), English as a language also brings its own unique culture and usage.

Just like many other languages within their culture, the use of the words in English is comprehensively covering many aspects of human desires and intentions. Means, the language is not solely to convey the message in complete utterances, but it can also use one word to cover other aspect of its use, including to express the message that represents psychological feelings.

To express the feeling, which could have the meaning of good feeling and uneasy feeling, there are several terms and words that are usually used, including the swear words. Swear words are the words that are included as profanity words and considered as offensive and usually used to express an anger or very upset condition (Jay \& Janschewitz, 2008). It was also said that due to their connotative meanings, those words were found to be very suitable to express the emotions, depends on the users' experience with the language and the language mastery itself.

Due to the ethic in educational field, or can be also from the reluctance of the teachers, many swear words that express bad feelings are not taught inside the classroom. It is of course arguable, whether or not to teach the words those express bad feeling to our students in schools. However, claiming that there is no way English teachers are allowed to inform the students about swearing words that could be part of sociolinguistic, socio-pragmatic, sociocultural field is an oversimplification (Dewaele, 2005), because the students will somehow know those words sooner or later through various media, such as movies, songs, and also from social network that provided by internet connection

The use of the words that are called swear words is not uncommon in this era (Thelwall, 2008), including in the institution where the use of these words are believed as the ignorance of their religious strong suggestion. In Islam, there is such as an explicit command says that "say good things or be silent". Other thing is, to express certain feeling in Islam, there are many words or terms that should be used because those words are believed as prayers that asking God's forgiveness or God's blessing to keep the heart calm, when it feels so bad.

This study is to know the students' perception on using ten swear words in their daily life. The students are from $5^{\text {th }}$ semester in English Education Department, Faculty of Tarbiyah and Teachers Training, State Islamic University, Jakarta. There are three $5^{\text {th }}$ semester classes.

Having get along with the students from various background has given the valuable experience knowing their problems including the personal ones. What English swear words do they know most? Do they use them? How often do they the words? Are they fine using the words? Do they realize that in their religion is strongly not suggested those swear words? What are the reasons they still use them if they do? What are their perceptions on using those swear words? These were the questions that would be the underlay of the research questions of this study. 


\section{LITERATURE REVIEW}

Using swear words was actually not something new in many cultures. However, the time and who was the interlocutor will limit the freedom of using it. It looked fine when the stars in movies did the conversation with lots of swearing words, but it would invite strong reaction from audience if it was used in more formal condition or at least when there were little children around the speakers (Dewaele, 2004). Even though swearing words were quite common in terms of daily use, it was very uncommon to find them in school textbooks because of their nature of being very offensive words. Therefore the students learned so little about those words and their usage (Dewaele, 2004) however there was no guarantee that they would not use them or just rarely used them.

Being non-native speakers did not mean immune to those swear or taboo words in the target language. Maybe they would not find the words in classroom setting, because in the ELT class, most of them had to learn good academic English with appropriate and "good" words. However it did not mean they would not find them when they were not in class. Even if they only visited an English speaking country for a short visitation such as holiday break, they would find those words through the interactions with the native speakers (Dewaele, 2004). It was also said that the non-native speakers would have more challenging task, the use of swearing words in their first language did not always have the same intention when it was said in the target language. Furthermore, using swearing words in target language could bring some misunderstanding due to the sensitivity in specific features in English pronunciation, such stress and intonation. It could be said that "...the proverb "when in Rome, do as Romans" did not necessarily apply to swearing in the TL" (Dewaele, 2004).

The tendency why people use swearing words was usually derived from certain feeling or emotion. The use of words was one of the most direct means of expressing thoughts and feelings (Fast \& Funder, 2008). However, hardly to be found out that every one of us used the same words for the same situation, because how we express (our feeling and emotion using) those words was a reflection of our psychological differences (Ickes W., 1997). The words in language were not only to be used in communication in common sense form, but they were also a particular type of expression (Cambridge Dictionaries Online, 2013). The other definition that explained the use of words in language to express the feeling was because it is a system that is used to express feeling and emotion to each other (Merriam Webster, 2013).

Sometimes it was thought that it become a little unfair in judging people's personality because of what they have said at certain moments of emotion then they were directly to be judged that's what they are. It should be well considered though because "Personality is an individual's enduring patterns of thought, emotion, and behavior" (Funder \& Ozer, 2007), and "...once individuals are in their chosen situation, their words and actions are genuine reflections of their personalities" (Ickes W., 1997).

When it came into the user of those swear words, it seemed that those who were in the transition process from a child into adult were the most people who use them, just to show they were different and wanted to be noticed (Drozde \& Vogule, 2008). They used language, style, attitude, and music as the sign of their protest against the norms of society and somehow their own very existence. However, age was not always the case of using the swear words, there were other reasons why people used them, including the "youth" feeling and the need to make closer relationship with the conversation partners (Drozde \& Vogule, 2008).

\section{METHOD}

The study was considered using qualitative method because it did not use any statistical calculation and only relied on survey result which used simple numerical calculation to describe its finding. The subjects of this study were the students at Fifth Semester from 2016 Academic Year, English Education Department, Faculty of Educational Sciences, "SyarifHidayatullah" State Islamic University Jakarta. The reason why they have been chosen to become the subjects was not only because they were the most accessible subject at the time of the study, but it was also because they had distinctive features as English students, they were teacher candidates from religious background university.

The data were collected using questionnaire. It was taken two times for different purposes. The first data collection was to get the general information on their background detail and to know how many swear words they have encountered. It was given to the whole class members (75 students). Their age was between 20 to 21 , with one student was 22 and one other was 19 years old. Meanwhile, the second questionnaire was to collect the data that was needed to answer the research questions and given only to 30 students. However, this study only discussed the result of the second data collection.

\section{RESULTS AND DISCUSSION}

From the first questionnaire distribution, there were more than thirty swearing words that were acknowledged by the students. Then the 10 most known words were used for the second questionnaire. In this study, gender was not used as a determining factor, even though it was believed that it would be an interesting research if there was a comparison of swear words usage based on gender because "The gender of the interlocutors is definitely one variable 


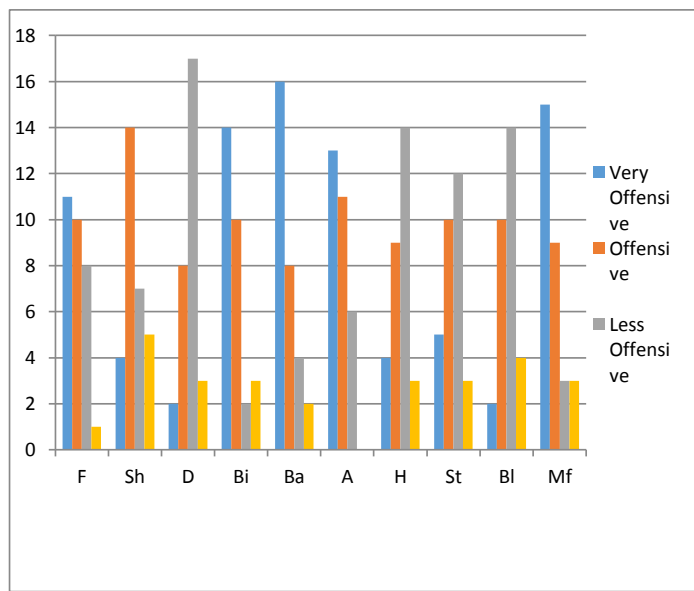

Graphic 1. What do the Students Think about the Swear Words

However, there were about two and three students that according to them, the SW Ba and Mf were not offensive. This could be because they have different environmental background (they mentioned that they have spent lots of time playing games that consist many dirty words), or as it was just mentioned in previous section, this could be one of the ways of the young people wanted to show they were different.

The different degree of offensiveness has long become the center of the study of language use (Baudhuin, 1973; Driscoll, 1981; Berger, 1970). It was because the words that were considered offensive was commonly defined as hurtful, derogatory, unfavorable, or obscene comments made by one person to another person (Wiegand, Siegel, \& Ruppenhofer, 2018). However, regarding the need to express emotions or feelings, the linguists put the swear words into several categories. Among others were those some mild words that were considered quite acceptable in certain circumstances, and some harsher words are deemed off-limits except perhaps in exceptional situations (Kaye \& Sapolsky, 2004).

\section{B. The Source of the Swear Words}

The second question asked how the students know about those SW.

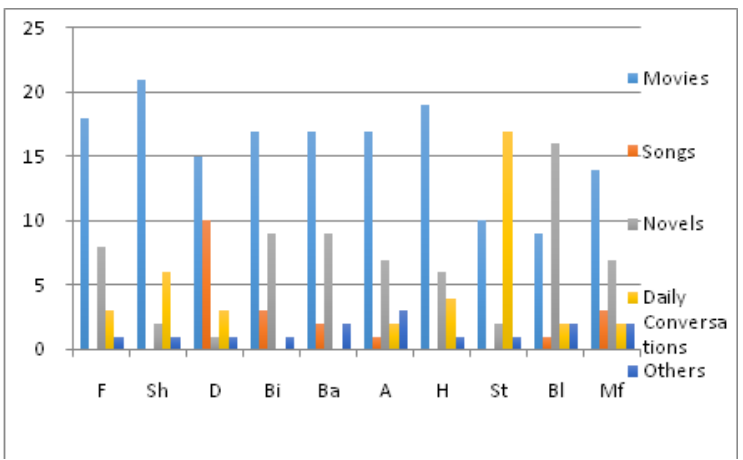

Graphic 2 Where the Students Get the Swear Words
From the graphic 1, it could be seen that the students were in agreement that the swear word (SW) Ba was the most offensive one, followed with slight differences by SW Mf and $\mathrm{Bi}$. It was probably because of their relevant meaning in Bahasa Indonesia are very "rude" and usually only come out of the mouth in the state of deep anger or hatred. Meanwhile, the SW D was considered as the least offensive, because the use of this SW was not only in term of swearing for bad things, but also in exaggerating something, such as "she's so damned beautiful", "damn, I forgot my homework", " I will not give a damn care about that matters". 
It seemed the movie was claimed as the most responsible one for the SW spreading for almost all SW. However, for SW H, Daily Conversation seemed the one that became the main source. Surprisingly, novels also became the source of the SW spreading. It could be seen from SW Bl that was acquired the most one from there. Meanwhile, Songs, were found out as did not have a very high contribution in SW spreading except for the SW D. Some students mentioned others as the sources, including social media network. It seemed that their interactions with their social surroundings in many forms of activity were the ultimate sources.

In this era, the students' social worlds as well as their everyday language use were highly consistent across time and context. They acquired the use of the language from many sources, especially from their social relationship. It was obvious that social contexts could strongly influence their behavior (Mehl \& Pennebaker, 2003). The use of SW among the young generations may influenced the perceived credibility, intensity, and persuasiveness of the swearer (Vingerhoets, Bylsma, \& Vlam, 2013). In addition, when the young people interchanged the use of SW, it could have a variety of interpersonal consequences, including promoting group bonding and solidarity, inhibiting aggression, eliciting humor, to get support or agreement from group members, and causing emotional pain to others.

\section{The Frequency in Using the Swear Words}

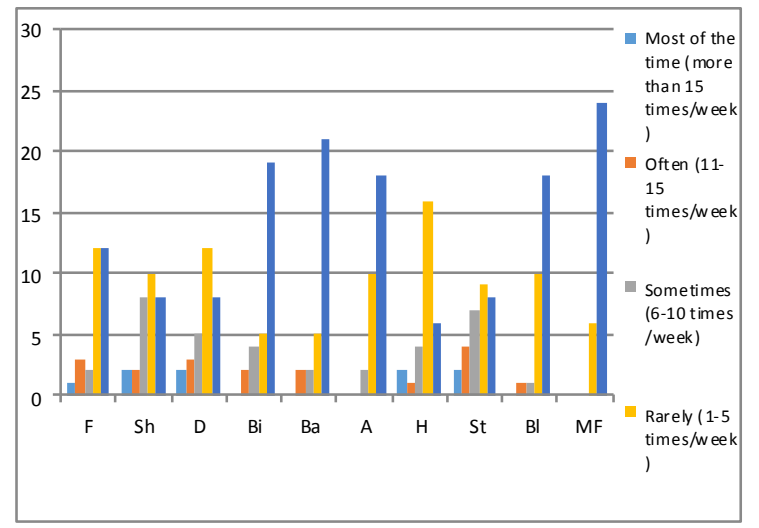

Graphic 3The Frequency in Using the Swear Words

From the graphic, it could be seen that, if we need to correlate between the SW they considered very offensive and the frequency of using them, they might have significantly high correlation. About 24 from 30 student said they never used the SW Mf, and the rest of them rarely used the. More than half samples also never used the $\mathrm{SW} \mathrm{Ba}$, followed by $\mathrm{SW} \mathrm{Bi}$ and $\mathrm{A}$ with a slight difference. Meanwhile, SW H, its highest frequency was rarely, which was also the most use from all SW. The influence of native language could be seen from the result of frequency use of SW F, Sh, D, A, and H because they have the equal meaning in Bahasa Indonesia.
Based on what it was believed that SW was usually used to express anger, emotions, or feelings (Jay \& Janschewitz, 2008), the frequency of people in using them will vary, depended on their social contexts (Mehl \& Pennebaker, 2003; Stephens \& Umland, 2017). Their culture and background would also influence the way they choose which SW to which situations or persons (Fägersten, 2007).

\section{The Psychological Condition When Using and After Using the Swear Words}

The next question asked about the psychological condition or the feeling that have made the students use the SW. Regarding to this question, not all the students answered it based on their own experience. Many of them stated that it was what they think if they had to use the SW. Some students also stated that they did not give the answer because they believe that they would never use those SW anyway.

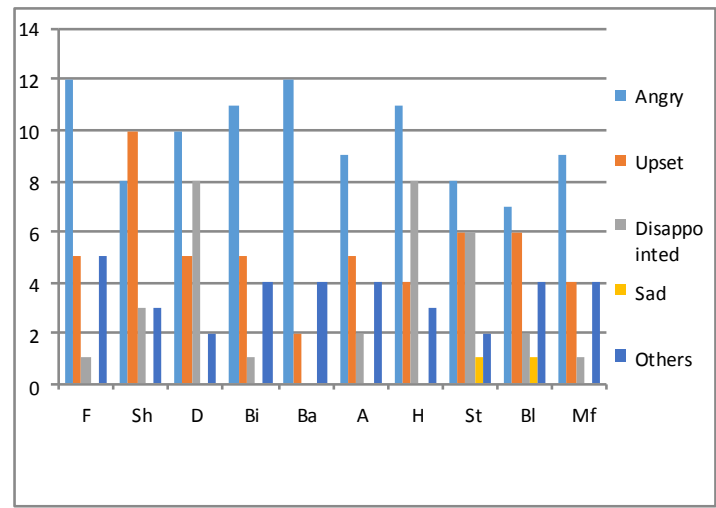

Graphic 4. The Psychological Condition when Using the Swear Words

Almost all SW were triggered by state of anger, with an exception for SW Sh which was mostly said when they were upset. It was quite understood because the equivalent meaning in Bahasa Indonesia was quite common heard in daily life. The same thing with SW $\mathrm{D}$ and $\mathrm{H}$, the reason Indonesian people using these SW in Bahasa Indonesia was mostly because they were disappointed.

The results was in agreement as it was stated in several studies, that the use of SW mostly related to mostly "negative" feelings (Berger, 1970; Driscoll, 1981; Ickes W., 1997; Jay \& Janschewitz, 2008), even though some also revealed that even "positive" could make someone utter some SWs (Mercury, 1995; Jay \& Janschewitz, 2008; Funder \& Ozer, 2007). 


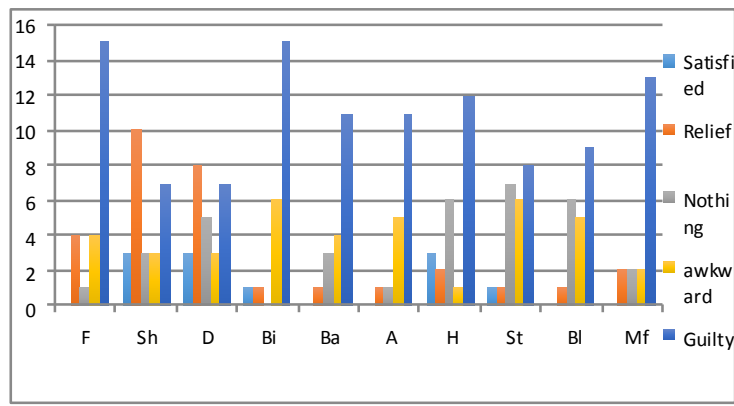

Graphic 5. Psychological Feeling after Saying the swear Words

Again, the answer from the students for this question did not necessarily mean that they really use the words. Quite many of them also preferred not to give any response to some SW. However, the tendency was shown that most of them would feel guilty after saying those SW, except for SW number 2 and 3, which their equivalent in Bahasa Indonesia was not as strong as other SW mentioned.

These word choices might reflect stable psychological processes; that was, they could be reflective of personality (Funder \& Ozer, 2007). It was also stated that the more they used the $\mathrm{SW}$, they may experience a hardened feeling because their pain tolerance was less compared to the time they do not use the SW (Stephens \& Umland, 2017).

E. Students' Feeling When Someone Use the Swear Words to Them

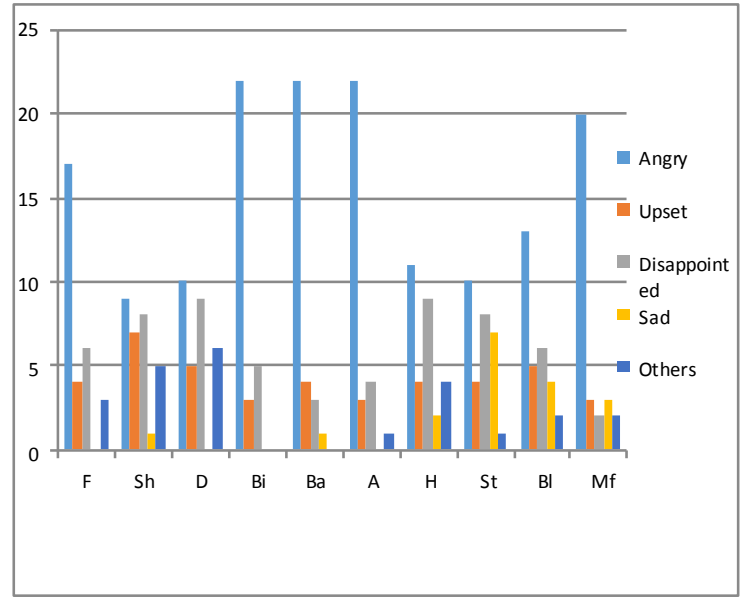

Graphic 6. Students' Feeling when SomeoneUse the Swear Words to Them

Based on the answers, most of the students felt angry if someone uses any of the SW to them. Only few stated that they felt sad. While for others, they mentioned shocked, nothing, and very angry, when someone using SW to them. Related to this, another question revealed the fact that most of the students (almost 90\%) had an agreement that they should avoid using SW, while the rest $(10 \%)$ were still in agreement that it was okay to use the SW, both to express the feeling and for the sake of social acknowledgement.

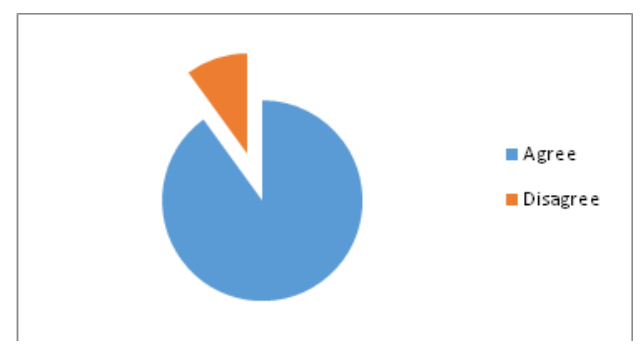

Diagram 1. The Agree and Disagree Position in Using SW

Furthermore, from the students' responses, it could be seen that they also do not feel comfortable toward those who use SW to them because it hurts them (Bartkevičienè \& Petniūnienè, 2008; Berger, 1970; Fast \& Funder, 2008; Dewaele, 2005). Majority of the student agreed that they have to avoid using SW. Some of the reasons were

- it is clear that it is strongly forbidden to utter such rude words

- $\quad$ every bad words we say will return to us

- $\quad$ it will hurt people's feeling

- there's no such example by the prophet so use it is a violation of the Prophet's Tradition (sunnah)

- we still have better terms to express our feeling including when we are very angry

- People is appreciated first by their appearance, second by what they say and the last is by their action.

Those who disagreed, said that they know that they must avoid using SW, however they still the need to express their feeling freely and adjust themselves in social life.

In Islam, and maybe in other religions, the followers were suggested to use good words or not to use the words that may hurt others. These were two examples from hadith (Prophet's Tradition) that suggest people to be wise in using the words; 1) A Muslim is the one who avoids harming Muslims with his tongue and hands; 2) Uqbah bin Amr said: I asked the Messenger of Allah SAW: "How can salvation be achieved?" He replied, "Control your tongue, keep to your house, and weep over your sins."

There were also some wise words from Scholars about the importance to take care of the words to be used, such as: 1) You find that the human beings tongue is so light, yet its power is so devastating. Ali bin Abi Thalib; 2) Only speak when your words are more beautiful than silence. - Dr. Bilal Philips.

Sometimes, those suggestions were followed with fore-warning reminder. As one of the examples, it was said that cursing or bad-mouthing to others is like a prayer which could backfire to the person who said it. 


\section{CONCLUSION}

Many of the students seemed know many form of swear words. From those swear words, there were 10 that were considered the most known. However, it did not mean they use them. For those who used the swear words, as the young people, the frequency was not really high, but of course it was debatable because it was a foreign language and they did not live in the environment that required them to use English as a mean of communication. For those who still use the words, they have their own different reasons and most of them felt guilty anyway after saying the SW because not only they realize it was forbidden, but they also realized that it hurt other people's feelings. Therefore, it could be said, they knew the SW was not good, yet they still had still use it to express their feelings and emotions.

Different result may come from different sample, such as the students' background, age, or types of school. The environment could also influence the different finding. The students that came from low SES family might have different habits or knowledge from the students of high SES family, even though they may study in the same public schools. Therefore, there were still a lot of area that could be explored to find out about the use of English swear words among EFL learners.

\section{REFERENCES}

[1] Bartkevičiene, R., \& Petniūnienė, N. (2008). Slang Vocabulary (Lexis)-A Reflection of Students' Being and Way of Life . Nation and Language: Modern Aspects of Socio-Linguistic Development (7-12). KTU Panevėžys Institute Centre of Languages.

[2] Baudhuin, E. S. (1973). Obscene language and evaluative response: An empirical study. Psychological Reports, 32, 399-402.

[3] Berger, A. A. (1970). Swearing and society. ETC: A Review of General Semantics , 30, 283-286.

[4] Cambridge Dictionaries Online. (2013, October). From http://dictionary.cambridge.org/dictionary/americanenglish/language

[5] Dewaele, J.-M. (2004). Blistering Barnacles! What Language do Multilinguals Swear in?! Estudios de Sociolinguistica 5, 83-105.

[6] Dewaele, J.-M. (2005). The Effect of Type of Acquisition Context on Perception and Selfreported Use of Swearwords in the L2, L3, L4 and L5. Investigation in Instructed Second Language Acquisition, 531-559.
Driscoll, J. M. (1981). Aggressiveness and frequency-ofaggressive-use ratings for pejorative epithets by Americans . The Journal of Social Psychology, 114, 111126.

[8] Drozde, L., \& Vogule, G. (2008). Censorship in Translation of Taboo Words. Nation and Language: Modern Aspects of Socio-Linguistics Development (hal. 21-28). KTU Panevėžys Institute Centre of Languages.

[9] Fägersten, K. B. (2007). A sociolinguistic analysis of swear word offensiveness. Saarland Working Papers in Linguistics, 1, 14-37.

[10] Fast, L. A., \& Funder, D. C. (2008). Personality as Manifest in Word Use: Correlations with Self Report, Acquaintance Report, and Behavior. Journal of Personality and Social Psychjology, 94, 334-346. doi:10.1037/0022-3514.94.2.334

[11] Funder, D. C., \& Ozer, D. J. (2007). Pieces of the Personality Puzzle: Readings in Theory and Research. WW Norton.

[12] Ickes W., S. M. (1997). Personality Influences on the Choice of Situations. Dalam J. J. R. Hogan, The Psychometrics of Social Life 869 Handbook of Personality Psychology (hal. 165-195). New York: Academic Press.

[13] Jay, T., \& Janschewitz, K. (2008). The pragmatics of swearing . Journal of Politeness Research. Language, Behaviour, $\quad$ Culture, 4(2), 267-288. doi:10.1515/JPLR.2008.013

[14] Kaye, B. K., \& Sapolsky, B. S. (2004). Talking a blue streak: Context and offensive language in prime time network television programs. Journalism \& Mass Communication Quarterly, 81(4), 911-927.

[15] Mehl, M. R., \& Pennebaker, J. W. (2003). The sounds of social life: A psychometric analysis of students' daily social environments and natural conversations. Journal of Personality and Social Psychology, 84(4), 857-870. doi:10.1037/0022-3514.84.4.857

[16] Mercury, R.-E. (1995). Swearing: A "Bad" Part of Language; A Good Part of Language Learning. TESL Canada Journauruvue TESL Du Canada, 13(1), 28-36.

[17] Merriam Webster. (2013, October). From http://www.merriam-webster.com/dictionary/language

[18] Stephens, R., \& Umland, C. (2017). Swearing as a response to pain-Effect of daily swearing. The Journal of Pain, 12(12), 1274-1281.

[19] Thelwall, M. (2008). Fk Yea I Swear: Cursing and Gender in a Corpus of MySpace Pages. Corpora, 83-107.

[20] Vingerhoets, A. J., Bylsma, L. M., \& Vlam, C. d. (2013). Swearing: A biopsychosocial perspective. Psychological Topics , 22(2), 287-304.

[21] Wiegand, M., Siegel, M., \& Ruppenhofer, J. (2018). Overview of the GermEval 2018 shared task on the identification of offensive language. Dalam J. M. Ruppenhofer (Penyunt.), GermEval 2018. 14th Conference on Natural Language Processing (KONVENS 2018) (hal. 1-10). Vienna: Austrian Academy of Sciences. 